\title{
Post-COVID-19 Late Pulmonary Embolism in a Young Woman about a Case
}

\section{Abdoulaye Touré1 ${ }^{*}$, Joseph Donamou², Amadou Yalla Camara², Boubacar Atigou Dramé1, Ousmane Aminata BAH ${ }^{3,4}$}

\author{
${ }^{1}$ Anesthesia-Intensive Care Unit, Ignace Deen Hospital, Conakry, Guinea \\ ${ }^{2}$ Anesthesia-Intensive Care Unit, Donka Hospital, Conakry, Guinea \\ ${ }^{3}$ Army Reference Imaging Center (CIRA), Conakry, Guinea \\ ${ }^{4}$ Chair of Biophysics and Medical Radiology-Imaging FSTS-University of Conakry, Conakry, Guinea \\ Email: *atfmamad@gmail.com
}

How to cite this paper: Touré, A., Donamou, J., Camara, A.Y., Dramé, B.A. and BAH, O.A. (2020) Post-COVID-19 Late Pulmonary Embolism in a Young Woman about a Case. Open Journal of Emergency Medicine, 8, 79-85.

https://doi.org/10.4236/ojem.2020.84009

Received: September 15, 2020 Accepted: November 16, 2020

Published: November 19, 2020

Copyright $\odot 2020$ by author(s) and Scientific Research Publishing Inc. This work is licensed under the Creative Commons Attribution International License (CC BY 4.0).

http://creativecommons.org/licenses/by/4.0/

\begin{abstract}
COVID-19 appears to be associated with a disproportionate risk of thrombosis. The occurrence of thrombosis is a frequent complication of many medical and surgical conditions. Their prevention by LMWH is the option of choice as well as their early diagnosis in this pandemic context. In addition, several recent observations support that severe pulmonary embolism is very common in hospitalized patients with COVID-19. We report the case of late pulmonary embolism in a 26-year-old patient with a medical history of (SARS-CoV2) and newly discovered diabetes. The clinical examination found exertional dyspnea, intense chest pain, blood pressure at $145 / 85 \mathrm{mmHg}$, heart rate at 129 bpm, respiratory rate at 25 cycles/min, blood sugar at $1.45 \mathrm{~g} / \mathrm{l}$, oxygen saturation at $92 \%$. In front of this clinical picture, the thoracic CT angiography to ask shows a pulmonary embolism of the right segmental and sub-segmental branches less marked on the left, involving the lingular and basal branches; the management was limited to anticoagulation associated with rehabilitation sessions (respiratory physiotherapy).
\end{abstract}

\section{Keywords}

Resuscitation, SARS-CoV2, Thromboembolism, Ignace Deen

\section{Introduction}

Coronavirus disease 2019 (COVID-19 or (SARS-CoV2) is a viral infection caused by "Severe Acute Respiratory Syndrome Coronavirus 2" which is a single-stranded RNA virus that enters the cells of the body via the receptor of the angiotensin-converting enzyme. This receptor is widely expressed in particular 
in pulmonary alveoli and vascular endothelium [1] [2]. SARS-CoV2 infection, particularly in ARDS arrays, appears to be associated with a large number of thromboembolic events. Most patients hospitalized for an infection (SARS-CoV2) are considered to be at high risk due to infection, bed rest, frequent respiratory decompensation or even co-morbidities. However, many questions remain open and are the source of very heterogeneous recommendations, both between hospitals and between learned societies [3] [4] [5]. In critically ill medical populations, the risk of venous thromboembolism extends beyond the duration of hospitalization, with up to $80 \%$ of events occurring in the post-hospital period ( 30 - 45 days) following index hospitalization [6]. SARS-CoV2 infection especially in ARDS arrays appears to be associated with a significant number of thromboembolic events. The object of this clinical case is to present the occurrence of a late pulmonary embolism in a young woman recovered from COVID-19.

\section{Patient and Observation}

A 26-year-old patient with a history of recently discovered diabetes during hospitalization for SARS-CoV2 declared cured on July 4, 2020. Anthropometric data: the patient weighed $92 \mathrm{~kg}$ for $179 \mathrm{~cm}\left(\mathrm{BMI}=28.7 \mathrm{~kg} / \mathrm{m}^{2}\right)$. She was treated from April 30 to July 3, 2020 at the Epidemiological Treatment Center (CTPI) at Donka National Hospital, where she received symptomatic treatment and the SARS-CoV2 treatment protocol consisting of hydroxychloroquine (200 mg $1 \mathrm{cp}$ $\times 3$ /day for 10 days) and azithromycin $(500 \mathrm{mg} 1 \mathrm{cp} /$ day then $250 \mathrm{mg} /$ day for 04 days), zinc $20 \mathrm{mg} /$ day for 10 days and Vitamin C $1000 \mathrm{mg}$ effervescent tablet $1 \mathrm{cp} /$ day in the morning. Her clinical condition improved under this treatment and after 20 days she was discharged from the hospital on July 4, 2020 after negating her twelfth PCR test. Four weeks later, she was admitted to the emergency room at Ignace Deen National Hospital with severe chest pain, dyspnea on exertion, and choking on speech. On arrival, the patient was aware and oriented. The initial clinical examination, in addition to the dyspnea, objectified to the cardiac auscultation a tachyarrhythmia with a frequency around 129/minute, the arterial pressure was at $145 / 85 \mathrm{~mm} \mathrm{Hg}$, an oxygen saturation of $92 \%$, a respiratory rate at 25 cycles/min and a blood sugar level of $1.45 \mathrm{~g} / \mathrm{l}$. Lung auscultation was normal and abdominal palpation was unremarkable. Furthermore, there was no peripheral congestive sign or jugular turgor, no hepatomegaly. On the cardiovascular level, we performed an electrocardiogram (ECG) which revealed sinus tachycardia. The QRS axis was not changed. There was no atrioventricular conduction disorder. The AP chest X-ray was normal. Biologically, we found a normochromic normocytic anemia with a hemoglobin level of $11.9 \mathrm{~g} / \mathrm{dl}$, a hematocrit at $34 \%$, platelets at $234 \mathrm{~g} / \mathrm{L}$ and leukocytes at $403,000 / \mathrm{mm}^{3}$, of which $31 \%$ were lymphocytes. The prothrombin level was $100 \%$ and the activated partial thromboplastin time was 1.4 times the control; INR at 0.98. Creatinine was $9.56 \mathrm{~g} / \mathrm{L} \mathrm{mmol} / \mathrm{L}$, urea $0.25 \mathrm{~g} / \mathrm{L}$; serum and serum potassium were normal. There 
was no hepatic cytolysis; pancreatic enzymes were normal; highly sensitive TSH $3.15 \mu \mathrm{IU} / \mathrm{ml}$; glycated hemoglobin $67.30 \mathrm{mmol} / \mathrm{mol}(8.30 \%)$ and the $\mathrm{D}$-dimer $17,000 \mathrm{ng} / \mathrm{ml}$.

Faced with this dyspnea, the thoracic CT scan performed revealed pulmonary embolism of the right segmental and sub-segmental branches, less marked on the left, involving the lingular and basal branches. An absence of pulmonary pleuroparenchymal abnormality (Figure 1). We continued the assessment with a cardiac Doppler ultrasound which had shown good systolic function of the LV, LVEF $=59 \%$ with Teicholz. A micro thrombus of $(11 \times 8 \mathrm{~mm})$ at the bifurcation of the left pulmonary artery and the right pulmonary artery occupying the initial portion of the right pulmonary artery without resonance. No pulmonary arterial hypertension or mitro-aortic valve disease and filling pressures were normal. In view of all these elements, the diagnosis of pulmonary embolism was retained.

The patient was subsequently transferred to the intensive care unit for treatment. We immediately started anticoagulant treatment with heparin (enoxaparin sodium $0.8 \mathrm{IU} \times 2 / \mathrm{d}$ for 4 days, overlapping on the second days with Rivaroxaban $20 \mathrm{mg} 1 \mathrm{tab} /$ day). At the same time, physiotherapy was carried out to promote recovery on the respiratory level. The patient was discharged from the intensive care unit on $\mathrm{D}+14$ on cardiological monitoring. After balancing his anticoagulant treatment and continuing his rehabilitation sessions (respiratory physiotherapy). The subsequent follow-up of the patient will be carried out for six (06) months by both cardiologists and pulmonologists.

\section{Discussion}

This case report describes an unusual case in which an established pulmonary embolism (PE) was detected only 47 days in a patient declared cured of SARS-CoV2 infection. From the beginning of March 2020, the problem of venous thrombosis during SARS-CoV2 quickly emerged as a major medical challenge since a significant rate of patients were thrombosed, some of whom despite well-conducted preventive anticoagulation [7]. The development of intrapulmonary microthrombi appears to be a particularly frequent complication of SARS-CoV2 [8] [9]. These micro thromboses would be the consequence of a severe intra-pulmonary inflammatory reaction (concept of immunothrombosis) [10]. The microthrombi observed in SARS-CoV2 are reminiscent of those of the syndromes of Thrombotic microangiopathies (MAT). However, thrombi from MAT affect many organs, whereas those from SARS-CoV2 are typically localized in the lungs. These intra-pulmonary microthrombi, however, are difficult to diagnose, including by imaging. The acronym PIC or Pulmonary Intravascular Coagulopathy [8] has been proposed to describe this entity. Many phenomena are mentioned and probably entangled in coagulopathy linked to COVID-19, including excess inflammation linked to the massive release of cytokines, activation of platelets, vascular stasis and endothelial dysfunction. Pre-existing comorbidities also form the basis of thrombotic events [11]. The virus uses the angiotensin-converting enzyme receptor (ACE 2 receptor) for its cell invasion. This 

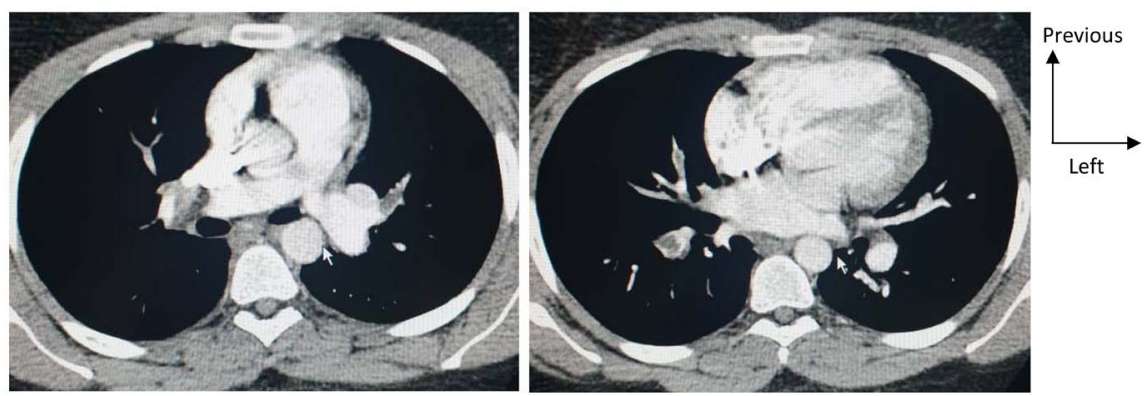

Figure 1. Thoracic Angio-CT scan, axial slice, mediastinal window central endo-luminal thrombi of predominantly right bilateral segmental and sub-segmental pulmonary arteries, indicating pulmonary embolism.

ubiquitous receptor is expressed on the surface of endothelial cells. Post-mortem histological analysis of 3 failed patients' multi-organism found endothelial inflammation in all affected organs (lung, kidneys, intestinal mucosa, heart) associated with the presence of the virus in these endothelial cells suggesting a direct involvement of the virus in the onset of endothelial dysfunction. This endothelial dysfunction could generate a systemic procoagulant state in addition to specific organ damage [12]. Endothelial dysfunction is a major determinant of microcirculatory dysfunction by altering the balance of the vascular bed balance towards more vasoconstriction generating ischemia, inflammation, edema and a procoagulant state. The high levels of von Willebrand factor vFW antigen and FVIII reported by the study by Helms et al. Advocate for significant endothelial inflammation [13]. Hypoxic vasoconstriction in itself may cause occlusion of small vessels. Hypoxia is also responsible for the synthesis of "Hypoxia Inducible Factors" (HIF) modifying and activating the synthesis of tissue factor and plasminogen-activator inhibitor 1 (PAI 1) [14] [15]. In our observation, this was a patient who had been staying with the virus for a long time with a recent discovery of diabetes. According to Tignanelli CJ et al., lesions caused by the virus at the level of endothelial cells could also play a role in the increased risk of thrombosis in COVID patients [16].

A Chinese retrospective study, involving 1008 patients from Wuhan, reported 25 patients with suspected pulmonary embolism who underwent CT angiography, of whom 10 were diagnosed with pulmonary embolism. D-dimers were higher in the "pulmonary embolism" group [17]. One of the main limitations is the lack of data on the methods used for thromboprophylaxis in these patients. Other data show significant biological disturbances in favor of coagulopathy such as increased D dimers and significant inflammatory syndrome [18] [19]. The general trend, in most countries, is for systematic thromboprophylaxis in the event of hospitalization for a SARS-CoV2 infection, as far as the hemorrhagic risk permits, which is not yet the case in the national strategy for Guinean response for simple hospitalizations.

Patients hospitalized with an acute medical condition are at risk for VTE. This risk is around $2 \%$ at 40 days after hospitalization [20]. The benefit of drug prophylaxis for $10 \pm 4$ days during hospitalization for an acute medical condi- 
tion was validated in the MEDENOX trial [21]. Thromboprophylaxis is currently recommended in all national and international good practice guidelines [22].

The question of prolonged thromboprophylaxis in patients discharged from hospital may arise if the risk persists. Several trials have tested this strategy for the prevention of venous thromboembolism. In the Exclaim trial, a 32\% reduction in the risk of venous thromboembolism was noted with preventive enoxaparin versus placebo [23]. In the Magellan trial which evaluates rivaroxaban 10 mg for 1 month, a reduction in the risk of venous thromboembolic events of $22 \%$ and a non-inferiority of rivaroxaban compared to enoxaparin but with an increased risk of bleeding for the patient is observed. rivaroxaban [24].

\section{Conclusion}

This observation demonstrates that the risk of late thromboembolism disease remains high in SARS-CoV2 patients even after recovery and especially when the terrain is predisposed. Thoracic CT should also be used in patients who are cured of SARS-CoV2 who present with dyspnea post SARS-CoV2 for pulmonary embolism, especially since data from the literature suggest a high thrombogenic potential of this infection.

\section{Authors' Contributions}

All authors have read and approved the final version of the manuscript.

\section{Conflicts of Interest}

The authors declare no conflicts of interest regarding the publication of this paper.

\section{References}

[1] Walls, A.C., Park, Y.-J., Tortorici, M.A., Wall, A., McGuire, A.T. and Veesler, D. (2020) Structure, Function, and Antigenicity of the SARS-CoV-2 Spike Glycoprotein. Cell, 181, 281-292.e6. https://www.ncbi.nlm.nih.gov/pmc/articles/PMC7102599 https://doi.org/10.1016/j.cell.2020.02.058

[2] Zhang, H., Penninger, J.M., Li, Y., Zhong, N. and Slutsky, A.S. (2020) Angiotensin-Converting Enzyme 2 (ACE2) as a SARS-CoV-2 Receptor: Molecular Mechanisms and Potential Therapeutic Target. Intensive Care Medicine, 46, 586-590. https://doi.org/10.1007/s00134-020-05985-9

[3] Thachil, J., Tang, N., Gando, S., et al. (2020) ISTH Interim Guidance on Recognition and Management of Coagulopathy in COVID-19. Journal of Thrombosis and Haemostasis, 18, 1023-1026. https://doi.org/10.1111/jth.14810

[4] Marietta, M., Ageno, W., Artoni, A., et al. (2020) COVID-19 and Haemostasis: A Position Paper from Italian Society on Thrombosis and Haemostasis (SISET). Blood Transfus, 18, 167-169.

[5] GFHT/GIHP (2020) Proposition pour le traitement anticoagulant pour la prévention du risque thrombotique chez un patient hospitalisé avec COVID-19. https://site.geht.org/docutheque

[6] Patell, R., Bogue, T., Koshy, A.G., Bindal, P., Merrill, M., Aird, W.C., et al. (2020) 
Post-Discharge Thrombosis and Hemorrhage in Patients with COVID-19. Blood, 136, 1342-1346. https://doi.org/10.1182/blood.2020007938

[7] Zuily, S., Dufrost, V. and Wahl, D. (2020) Thrombose artérielle et veineuse au cours du COVID-19. Archives des Maladies du Coeur et des Vaisseaux-Pratique, 2020,

16-19. https://www.ncbi.nlm.nih.gov/pmc/articles/PMC7413116

https://doi.org/10.1016/j.amcp.2020.08.003

[8] Fogarty, H., Townsend, L., Ni, C.C., Bergin, C., Martin-Loeches, I., Browne, P., et al. (2020) COVID-19 Coagulopathy in Caucasian Patients. British Journal of Haematology, 189, 1044-1049. https://doi.org/10.1111/bjh.16791

[9] Levi, M., Thachil, J., Iba, T. and Levy, J.H. (2020) Coagulation Abnormalities and Thrombosis in Patients with COVID-19. The Lancet Haematology, 7, E438-E440.

[10] Leisman, D.E., Deutschman, C.S. and Legrand, M. (2020) Facing COVID-19 in the ICU: Vascular Dysfunction, Thrombosis, and Dysregulated Inflammation. Intensive Care Medicine, 46, 1105-1108. https://doi.org/10.1007/s00134-020-06059-6

[11] Mehta, P., McAuley, D.F., Brown, M., Sanchez, E., Tattersall, R.S. and Manson, J.J. (2020) COVID-19: Consider Cytokine Storm Syndromes and Immuno-Suppression. The Lancet, 395, 1033-1034. https://doi.org/10.1016/S0140-6736(20)30628-0

[12] Varga, Z., Flammer, A.J., Steiger, P., Haberecker, M., Ander-Matt, R., Zinkernagel, A.S., et al. (2020) Endothelial Cell Infection and Endotheliitis in COVID-19. The Lancet, 395, 1417-1418. https://doi.org/10.1016/S0140-6736(20)30937-5

[13] Helms, J., Tacquard, C., Severac, F., Leonard-Lorant, I., Ohana, M., Merdji, H., et al. (2020) High Risk of Thrombosis in Patients in Severe SARS-CoV-2 Infection: A Multicenter Prospective Cohort Study. Intensive Care Medicine, 46, 1089-1098. https://doi.org/10.1007/s00134-020-06062-X

[14] Yan, S.F., Mackman, N., Kisiel, W., Stern, D.M. and Pinsky, D.J. (1999) Hypoxia/Hypoxemia-Induced Activation of the Procoagulant Pathways and the Pathogenesis of Ischemia-Associated Thrombosis. Arteriosclerosis, Thrombosis, and Vascular Biology, 19, 2029-2035. https://doi.org/10.1161/01.ATV.19.9.2029

[15] Gupta, N., Zhao, Y.-Y. and Evans, C.E. (2019) The Stimulation of Thrombosis by Hypoxia. Thrombosis Research, 181, 77-83. https://doi.org/10.1016/j.thromres.2019.07.013

[16] Tignanelli, C.J., et al. (2020) Antihypertensive Drugs and Risk of COVID-19? The Lancet Respiratory Medicine, 8, e30-e31. http://www.thelancet.Com/respiratory

[17] Chen, N., Zhou, M., Dong, X., Qu, J., Gong, F., Han, Y., et al. (2020) Epidemiological and Clinical Characteristics of 99 Cases of 2019 Novel Coronavirus Pneumonia in Wuhan, China: A Descriptive Study. The Lancet (London, England), 395, 507-513. https://doi.org/10.1016/S0140-6736(20)30211-7

[18] Tang, N., Li, D., Wang, X. and Sun, Z. (2020) Abnormal Coagulation Parameters Are Associated with Poor Prognosis in Patients with Novel Coronavirus Pneumonia. Journal of Thrombosis and Haemostasis, 18, 844-847. https://doi.org/10.1111/jth.14768

[19] Zhou, F., Yu, T., Du, R., Fan, G., Liu, Y., Liu, Z., et al. (2020) Clinical Course and Risk Factors for Mortality of Adult Inpatients with COVID-19 in Wuhan, China: A Retrospective Cohort Study. The Lancet (London, England), 395, 1054-1062. https://doi.org/10.1016/S0140-6736(20)30566-3

[20] Amin, A.N., Varker, H., Princic, N., Lin, J., Thompson, S. and Johnston, S. (2012) Duration of Venous Thromboembolism Risk across a Continuum in Medically Ill Hospitalized Patients. Journal of Hospital Medicine, 7, 231-238. https://doi.org/10.1002/jhm.1002 
[21] Samama, M.M., Cohen, A.T., Darmon, J.Y., Desjardins, L., Eldor, A., Janbon, C., et al. (1999) A Comparison of Enoxaparin with Placebo for the Prevention of Venous Thromboembolism in Acutely Ill Medical Patients. Prophylaxis in Medical Patients with Enoxaparin Study Group. New England Journal of Medicine, 341, 793-800. https://doi.org/10.1056/NEJM199909093411103

[22] Kearon, C., Akl, E.A., Ornelas, J., Blaivas, A., Jimenez, D., Bounameaux, H., et al. (2016) Antithrombotic Therapy for VTE Disease: CHEST Guideline and Expert Panel Report. Chest, 149, 315-352. https://doi.org/10.1016/j.chest.2015.11.026

[23] Hull, R.D., Schellong, S.M., Tapson, V.F., Monreal, M., Samama, M.-M., Nicol, P., et al. (2010) Extended-Duration Venous Thromboembolism Prophylaxis in Acutely Ill Medical Patients with Recently Reduced Mobility: A Randomized Trial. Annals of Internal Medicine, 153, 8-18.

https://doi.org/10.7326/0003-4819-153-1-201007060-00004

[24] Cohen, A.T., Spiro, T.E., Büller, H.R., Haskell, L., Hu, D., Hull, R., et al. (2013) Rivaroxaban for Thromboprophylaxis in Acutely Ill Medical Patients. New England Journal of Medicine, 368, 513-523. https://doi.org/10.1056/NEJMoa1111096 